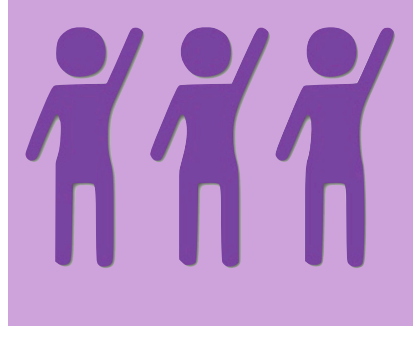

\title{
Aborto legal interseccionalidades para garantia de um cuidado humanizado
}

No Brasil, o aborto legal é restrito, sendo realizado somente em três situações quando a gravidez implica risco de morte à mulher e quando resulta de estupro em casos de comprovação de anencefalia fetal. Com isso, as mulheres são empurradas para realização do aborto clandestino, que muitas vezes são realizados de forma insegura e são as mulheres negras, de baixa escolaridade da região Norte e Nordeste que estão submetidas a essa situação.

Por outro lado, mesmo com direito ao aborto permitido por lei as mulheres estão expostas as barreiras pessoais e institucionais, pois o estigma do aborto e a discriminação as colocam em situação de vulnerabilidade e violências institucionais. Ao mesmo tempo que a criminalização prejudica também o aborto previsto em lei. Vale destacar que estudos realizados nos países em que o aborto é legal evidenciam que o estigma, as desigualdades sociais, o racismo são fatores fundamentais prejudicando o acesso das mulheres aos serviços de saúde, as conduzindo para o aborto inseguro (GOES, 2018; GANATRA; FAUNDES, 2016; DORAN; NANCARROW, 2015).

No Brasil no ano de 2016 houve 195.860 internações por consequências do aborto e $62,4 \%$ dos casos eram mulheres negras (dados do Sistema de Morbidade Hospitalar do Ministério da Saúde), mesmo com a legalização restrita ao aborto, o Estado prevê uma atenção humanizada para as mulheres em situação de abortamento, a partir dos marcos ético e jurídico dos direitos sexuais e reprodutivos afirmados nos planos internacional e nacional de direitos humanos, tendo como princípios norteadores a igualdade, a liberdade e a dignidade da pessoa humana, não se admitindo qualquer discriminação ou restrição ao acesso à assistência à saúde, como consta na Norma Técnica Atenção Humanizada ao Abortamento (BRASIL, 2005).

Este dossiê dialoga com os debates atuais sobre a legalização do aborto no Brasil, pois essa agenda no escopo mais amplo dos direitos 
reprodutivos, tem se intensificado na América Latina, mais recente (2018) as feministas Argentinas foram para rua pela legalização do aborto sobre o lema "Educação sexual para decidir, anticoncepcionais para não abortar, aborto legal para não morrer”. No mesmo ano no Brasil tivemos a arguição de descumprimento de preceito fundamental (ADPF 442) que na qual se discute a descriminalização do aborto até a $12^{\mathrm{a}}$ semana de gestação. A ADPF 442 teve efetiva participação dos movimentos feministas e movimento de mulheres que apresentou um posicionamento a partir das dinâmicas interseccionais de raça, gênero, classe, região e geração que atravessam o percurso reprodutivo das mulheres, a autonomia reprodutiva e a tomada de decisão pela gravidez ou pelo aborto.

Os artigos apresentados no Dossiê Aborto legal: Interseccionalidades para garantia de um cuidado humanizado tem como finalidade ampliar os debates e as vozes de ativistas e pesquisadoras neste tema que é tão espinhoso e necessário. $\mathrm{O}$ aborto legal precisa ser visto para além das leis, mas nas relações das/os profissionais e trabalhadoras/es da saúde é necessário despir todas as discriminações e estigmas que interagem, estruturam e hierarquizam a atenção, sujeitando as mulheres em situação de abortamento as mais diversas formas de violências (institucionais e obstétricas). O aborto é uma questão de saúde pública, de direitos humanos e acima de tudo é sobre a autonomia e a vida das mulheres.

Aline Alves VELEDA Emanuelle Freitas GóES

\section{Referências}

BRASIL. Norma Técnica de Atenção Humanizada ao Abortamento: norma tecnica. Brasilia: Ministério da Saúde (MS), 2005.

DORAN, F.; NANCARROW, S. Barriers and facilitators of access to firsttrimester abortion services for women in the developed world: a systematic review. Journal of Family Planning and Reproductive Health Care, v. 41, n. 3, p. 170-180, 2015. 
GANATRA, B.; FAUNDES, A. Role of birth spacing, family planning services, safe abortion services and post-abortion care in reducing maternal mortality. Best Practice \& Research Clinical Obstetrics \& Gynaecology, v. 36, p. 145-155, out. 2016.

GOES, E. F. Racismo, aborto e atenção à saúde: uma perspectiva interseccional. 105f. Tese (Doutorado Saúde Pública) - Instituto de Saúde Coletiva, Universidade Federal da Bahia, Salvador, 2018. 